\title{
Role of Beclin-1-Mediated Autophagy in the Survival of Pediatric Leukemia Cells
}

\author{
Xiaoli Wu Xuefeng Feng $^{\mathrm{b}}$ Xiaoqing Zhao ${ }^{\mathrm{a}}$ Futian $\mathrm{Ma}^{\mathrm{a}}$ Na $\mathrm{Liu}^{\mathrm{a}}$ Hongming Guo $^{\mathrm{a}}$ \\ Chaonan Lia Huan Duª Baoxi Zhang ${ }^{a}$ \\ aDepartment of Pediatrics Hematology-Oncology, the Second Hospital of Hebei Medical University, \\ Shijiazhuang, ${ }^{b}$ Department of Hematology, the Second Hospital of Hebei Medical University, \\ Shijiazhuang, China
}

\section{Key Words}

Pediatric leukemia $(\mathrm{PL}) \cdot$ Oxidative stress • Autophagy • Apoptosis • Beclin-1 • miR-93

\begin{abstract}
Background/Aims: Acute and chronic leukemia are severe malignant cancers worldwide, and can occur in pediatric patients. Since bone marrow cell transplantation is seriously limited by the availability of the immune-paired donor sources, the therapy for pediatric leukemia $(\mathrm{PL})$ remains challenging. Autophagy is essential for the regulation of cell survival in the harsh environment. However, the role of autophagy in the survival of PL cells under the oxidative stress, e.g. chemotherapy, remain ill-defined. In the current study, we addressed these questions. Methods: We analyzed the effects of oxidative stress on the cell viability of PL cells in vitro, using a CCK-8 assay. We analyzed the effects of oxidative stress on the apoptosis and autophagy of PL cells. We analyzed the levels of Beclin- 1 and microRNA-93 (miR-93) in PL cells. Prediction of binding between miR-93 and 3'-UTR of Beclin-1 mRNA was performed by a bioinformatics algorithm and confirmed by a dual luciferase reporter assay. The relationship between levels of miR-93 and patients' survival was analyzed in PL patients. Results: We found that oxidative stress dose-dependently increased autophagy in $\mathrm{PL}$ cells. While low-level oxidative stress did not increase apoptosis, high-level oxidative stress increased apoptosis, seemingly from failure of autophagy-mediated cell survival. High-level oxidative stress appeared to suppress the protein levels of an autophagy protein Beclin-1 in PL cells, possibly through induction of miR-93, which inhibited the translation of Beclin-1 mRNA via 3'-UTR binding. Conclusion: Beclin-1-mediated autophagy plays a key role in the survival of $\mathrm{PL}$ cells against oxidative stress. Induction of miR-93 may increase the sensitivity of PL cells to oxidative stress during chemotherapy to improve therapeutic outcome.
\end{abstract}

\section{Introduction}

Leukemia is a severe malignant cancer worldwide [1]. Although leukemia is mainly detected in adults, some are indeed detected during pediatric period as pediatric leukemia (PL) [1]. The etiology and pathology of leukemia in children remain elusive [2-5]. However, 
some evidence have shown that leukemia in children with Down syndrome (DS) possesses a GATA1 mutation that cooperates with trisomy 21 , followed by the acquisition of additional somatic mutations in epigenetic and kinase signaling genes [6-8]. This represents a transient over-proliferation of myeloid cells at the early years of life, followed by either spontaneous resolution or development into leukemia in a portion of patients [6-8]. However, there are other types of leukemia with unknown causes. Moreover, current therapies with bone marrow cell transplantation are seriously limited by the availability of immune-paired donor sources $[9,10]$. Hence, development of efficient therapy independent of bone marrow transplantation, e.g. a specific chemotherapy, may substantially improve the therapeutic outcomes.

The resistance of leukemia to chemotherapy may result from enhanced anti-apoptotic potentials of the cancer cells in a particular setting [11-13]. Cellular apoptosis is regulated by apoptosis activating proteins, e.g. Bid, Bak, Bad, and apoptosis suppressors, e.g. Bcl-2 [14-20]. Autophagy is a catabolic biological event characterized by the degradation of the cellular compartments and their recycling in order to improve cell survival upon harsh living environment [21-25]. Among all autophagy-associated proteins, autophagy-associated protein 6 (ATG6, or Beclin-1) is a key regulator [26]. Recent studies have demonstrated a critical role of autophagy in the tumor initiation, growth and metastases, and especially in the mechanisms underlying chemo-resistance of tumor cells during chemotherapy [27-30]. Nevertheless, autophagy has not been extensively studied for its association with chemoresistance of PL cells.

MicroRNAs (miRNAs) are a class of non-coding small RNAs that regulate the protein translation of target mRNA at the $3^{\prime}$-untranslated region (3'-UTR) [31, 32]. There are accumulating evidence showing that miRNAs play very important roles in tumor [33-35]. Among all miRNAs, the involvement of miR-93 as either a tumor enhancer [36, 37], or a tumor suppressor [38-40] in various cancers has been reported. However, the role of miR-93 in the chemo-resistance of PL cells against oxidative stress has not been studied.

In the current study, we aimed to analyze the association between apoptotic cell death and autophagic cell survival of PL cells in response to oxidative stress, which is the major mechanism for killing cancer cells during chemotherapy.

\section{Materials and Methods}

\section{Experimental protocol approval}

All experimental protocols were approved by the Research Bureau of the Second Hospital of Hebei Medical University. The experiments were carried out in accordance with the approved guidelines based on the Declaration of Helsinki.

\section{Patient tissue specimens}

Forty PL specimens in this study were histologically and clinically diagnosed at the Second Hospital of Hebei Medical University from 2010 to 2014. For the use of these clinical materials for research purposes, informed consent was obtained from all subjects, and approval from the Institutional Research Ethics Committee were obtained. The methods were carried out in accordance with the approved guidelines.

\section{Cell lines and reagents}

Kasumi-4 and 8E5 were two PL cell lines purchased from ATCC (ATCC, Rockville, MD, USA), and were cultured in Dulbecco's Modified Eagle's Medium (DMEM) supplemented with 20\% fetal bovine serum (Invitrogen, Carlsbad, CA, USA) in a humidified chamber with $5 \% \mathrm{CO}_{2}$ at $37^{\circ} \mathrm{C}$. The Kasumi- 4 cell line was established from the peripheral blood of an chronic myeloblastic leukemia patient of 6 year-old female Japanese individual. The $8 \mathrm{E} 5$ cell line was derived from acute lymphoblastic leukemia cells obtained from the pleural effusion of a 4 year-old female Caucasian patient. These two lines have been widely used for studying PL. Hydrogen peroxide $\left(\mathrm{H}_{2} \mathrm{O}_{2}\right.$, Sigma-Aldrich, St. Louis, MO, USA) was applied to the cultured PL cells at $0,0.5,2$ and $5 \mathrm{mmol} / \mathrm{l}$, respectively. 3-Methyladenine (3-MA, Sigma-Aldrich) was prepared and used fresh at a concentration of $5 \mathrm{mmol} / \mathrm{l}$. 


\section{Cellular Physiology Cell Physiol Biochem 2016;39:1827-1836 \begin{tabular}{ll|l} 
DOI: 10.1159/000447882 & $\begin{array}{l}\text { O 2016 The Author(s). Published by S. Karger AG, Basel } \\
\text { wwww.karger.com/cpb }\end{array}$ \\
\hline and Biochemistry
\end{tabular} \\ Wu et al.: Autophagy in PL Cell Survival}

\section{Cell transfection}

MiRNAs mimics (miR-93) and miRNAs antisense oligonucleotides (as-miR-93) were obtained from Origene (Beijing, China). For a control of these plasmids for modifying miR-93 levels, a plasmid carrying a null sequence (null) was used. These constructs were generated and cloned into the TOPO plasmid (Invitrogen, Carlsbad, CA, USA). The plasmids were transfected into cells at a concentration of $50 \mathrm{nmol} / \mathrm{l}$ using Lipofectamine-2000 (Invitrogen), receiving a 95\% transfection efficiency. The cells were analyzed after 24 hours, according to the manufacturer's instruction.

MicroRNA target prediction and 3'-UTR luciferase-reporter assay

MiRNAs targets were predicted with the algorithms TargetSan (https://www.targetscan.org) [41]. Luciferase-reporters were successfully constructed using molecular cloning technology. The Beclin-1 3'UTR reporter plasmid (Beclin-1 3'-UTR) and Beclin-1 3'-UTR reporter plasmid with a mutant at the miR-93 binding site (Beclin-1 3'-UTR mut) were purchased from Creative Biogene (Shirley, NY, USA). PL cells were co-transfected with Beclin-1 3'-UTR/Beclin-1 3'-UTR mut and miR-93/as-miR-93/null by Lipofectamine $2000\left(5 \times 10^{4}\right.$ cells per well). Cells were collected 24 hours after transfection for assay using the dualluciferase reporter assay (Promega, Beijing, China), according to the manufacturer's instructions.

\section{Cell counting kit-8 (CCK-8) assay}

The CCK-8 detection kit (Sigma-Aldrich) was used to measure cell viability according to the manufacturer's instructions. Briefly, cells were seeded in a 96-well microplate at a density of 5000/ml. After $24 \mathrm{~h}$, cells were treated with resveratrol. Subsequently, CCK-8 solution $(20 \mathrm{ml} /$ well) was added and the plate was incubated at $37^{\circ} \mathrm{C}$ for $2 \mathrm{~h}$. The viable cells were counted by absorbance measurements with a microplate reader at a wavelength of $450 \mathrm{~nm}$. The optical density value was reported as the percentage of cell viability in relation to the control group (set as $100 \%$ ).

\section{Apoptosis assay by flow cytometry}

For analysis of cell proliferation, the dissociated tissue cells or cultured cells were re-suspended at a density of $10^{6}$ cells $/ \mathrm{ml}$ in PBS. After double staining with FITC-Annexin V and propidium iodide (PI) from a FITC Annexin V Apoptosis Detection Kit I (Becton-Dickinson Biosciences, San Jose, CA, USA), cells were analyzed using FACScan flow cytometer (Becton-Dickinson Biosciences) equipped with Cell Quest software (Becton-Dickinson Biosciences) for determination of Annexin V+ PI- apoptotic cells.

\section{Western blot}

Protein was extracted from the cultured cells with RIPA lysis buffer (Sigma-Aldrich) on ice. The supernatants were collected after centrifugation at $12000 \times \mathrm{g}$ at $4^{\circ} \mathrm{C}$ for $20 \mathrm{~min}$. Protein concentration was determined using a BCA protein assay kit (Bio-rad, China), and the proteins were separated on SDSpolyacrylamide gels, and then transferred to a PVDF membrane. The membrane blots were first probed with a primary antibody. After incubation with horseradish hydrogen peroxide-conjugated second antibody, enhanced chemiluminescent system was applied to visualize the protein antigen. Primary antibodies were rabbit anti-Beclin-1 and anti- $\alpha$-tubulin (Cell Signaling, San Jose, CA, USA). Secondary antibody is HRPconjugated anti-rabbit (Jackson ImmunoResearch Labs, West Grove, PA, USA). $\alpha$-tubulin was used as a protein loading control. The protein levels were first normalized to $\alpha$-tubulin, and then normalized to the experimental controls.

\section{Quantitative real-time PCR (RT-qPCR)}

Total RNA was extracted from cultured cells using miRNeasy kit (Qiagen), for cDNA synthesis. Quantitative real-time PCR (RT-qPCR) was performed in duplicates with QuantiTect SYBR Green NSCLCR Kit (Qiagen). All primers were purchased from Qiagen. Data were collected and analyzed with ${ }^{2-\Delta \Delta} \mathrm{Ct}$ method for quantification. Values of genes were first normalized against $\alpha$-tubulin, and then compared to experimental controls.

Statistical analysis

All data were statistically analyzed using one-way ANOVA with a Bonferroni correction, followed by Fisher's Exact Test for comparison of two groups (GraphPad Prism, GraphPad Software, Inc. La Jolla, 


\section{Cellular Physiology Cell Physiol Biochem 2016;39:1827-1836

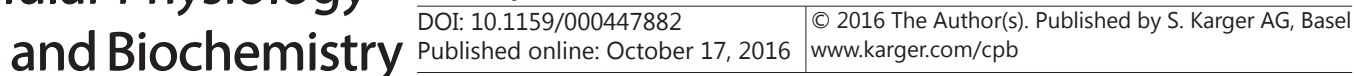 \\ Wu et al.: Autophagy in PL Cell Survival}

CA, USA). Kaplan-Meier curves were used to analyze the patient survival by miR-93 levels. All values are depicted as mean \pm standard deviation and are considered significant for $\mathrm{p}<0.05$.

\section{Results}

High hydrogen peroxide increases PL cell apoptosis

We uses hydrogen peroxide as an oxidase stress to mimic the effect of chemotherapy on PL cells. Thus, we examined the effects of hydrogen peroxide on PL cell apoptosis using 2 PL cell lines, 8E5 and Kasumi-4. We gave hydrogen peroxide at different doses (0, 0.5, 2 and $5 \mathrm{mmol} / \mathrm{l}$, respectively) to the PL cells. We found that hydrogen peroxide did not appear to increase 8E5 cell apoptosis at low doses ( 0.5 and $2 \mathrm{mmol} / \mathrm{l})$, but significantly increased $8 \mathrm{E} 5$ cell apoptosis at high dose ( $5 \mathrm{mmol} / \mathrm{l})$, shown by quantification (Fig. 1A), and by representative flow charts (Fig. 1B). Similarly, we found that hydrogen peroxide did not appear to increase Kasumi-4 cell apoptosis at low doses ( 0.5 and $2 \mathrm{mmol} / \mathrm{l})$, but significantly increased Kasumi-4 cell apoptosis at high dose $(5 \mathrm{mmol} / \mathrm{l})$, shown by quantification (Fig. 1C), and by representative flow charts (Fig. 1D).

Suppression of autophagy increases hydrogen peroxide-induced PL cell death at low dose

We next examined the effects of hydrogen peroxide on PL cell survival to see whether PL cell autophagy may be responsible for the little increases in cell apoptosis by low-dose hydrogen peroxide. For this purpose, we examined the effects of hydrogen peroxide on PL cell death also when autophagy is inhibited. We gave hydrogen peroxide at different doses $(0,0.5,2$ and $5 \mathrm{mmol} / \mathrm{l}$, respectively) to PL cells, with or without an autophagy inhibitor
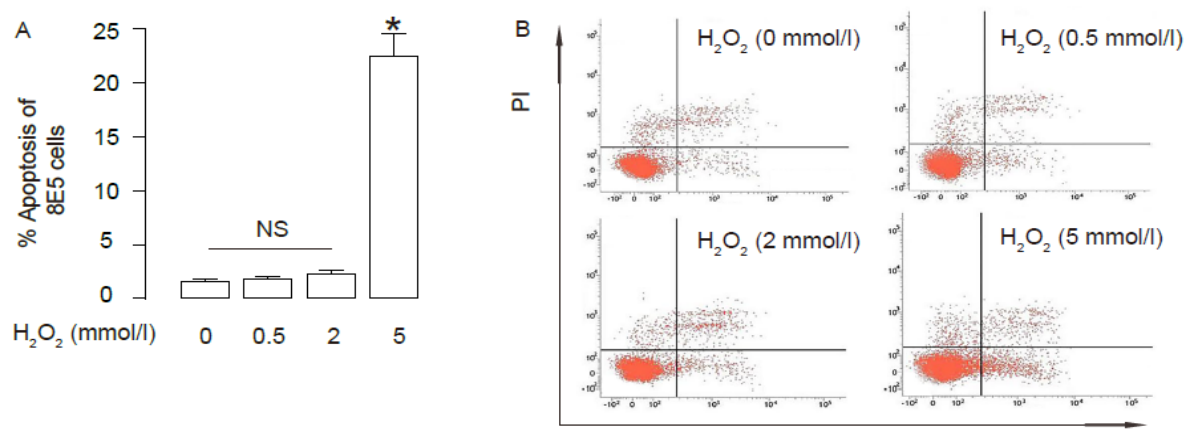

Annexin-FITC
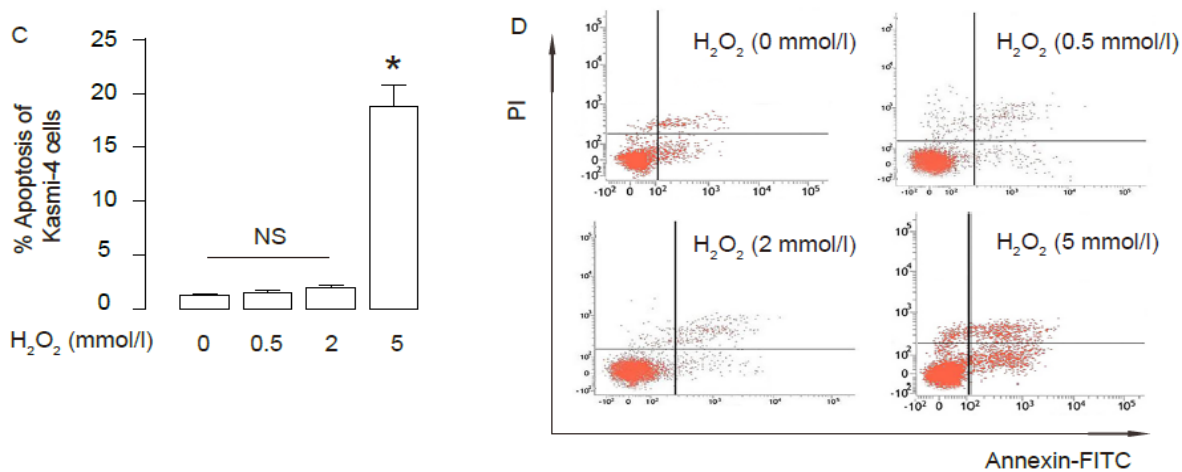

Fig. 1. High hydrogen peroxide increases PL cell apoptosis. The effects of hydrogen peroxide on apoptosis in 2 PL cell lines, 8E5 and Kasumi-4. We gave hydrogen peroxide at different doses (0, 0.5, 2 and 5mmol/l, respectively) to the PL cells. (A-B) $8 \mathrm{E} 5$ cell apoptosis, shown by quantification (A), and by representative flow charts (B). (C-D) Kasumi-4 cell apoptosis, shown by quantification (C), and by representative flow charts (D). ${ }^{*} \mathrm{p}<0.05$. NS: non-significant. $\mathrm{N}=5$. 


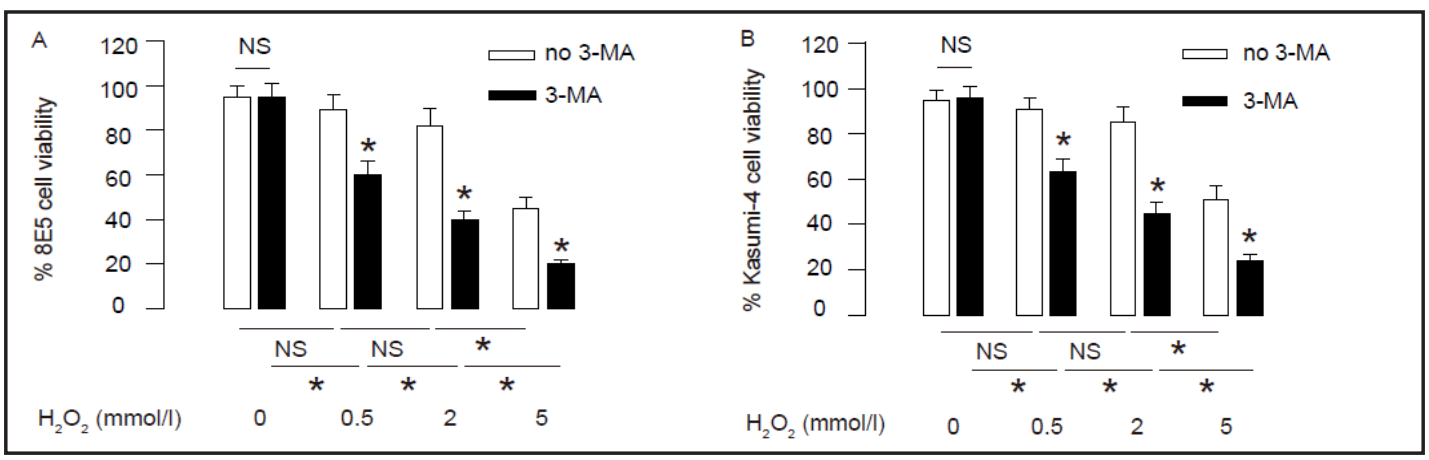

Fig. 2. Suppression of autophagy increases hydrogen peroxide-induced PL cell death at low dose. We gave hydrogen peroxide at different doses $(0,0.5,2$ and $5 \mathrm{mmol} / \mathrm{l}$, respectively) to PL cells, with or without an autophagy inhibitor 3-MA (5mmol/l). (A) $8 \mathrm{E} 5$ cell survival in an CCK-8 assay. (B) Kasumi-4 cell survival in an CCK-8 assay. ${ }^{*} \mathrm{p}<0.05$. NS: non-significant. $\mathrm{N}=5$.

Fig. 3. Hydrogen peroxide increases Beclin-1 to activate PL autophagy. We gave hydrogen peroxide at different doses $(0$, $0.5,2$ and $5 \mathrm{mmol} / \mathrm{l}$, respectively) to $\mathrm{PL}$ cells, with or without an autophagy inhibitor 3-MA (5mmol/l). (A) Beclin-1 protein in 8 E5 cells by Western blot. (B) Beclin-1 mRNA in 8E5 cells by RT-qPCR. (C) Beclin-1 protein in Kasumi-4 cells by Western blot. (D) Beclin-1 mRNA in Kasumi-4 cells by RT-qPCR. * $p<0.05$. NS: non-significant. $\mathrm{N}=5$.

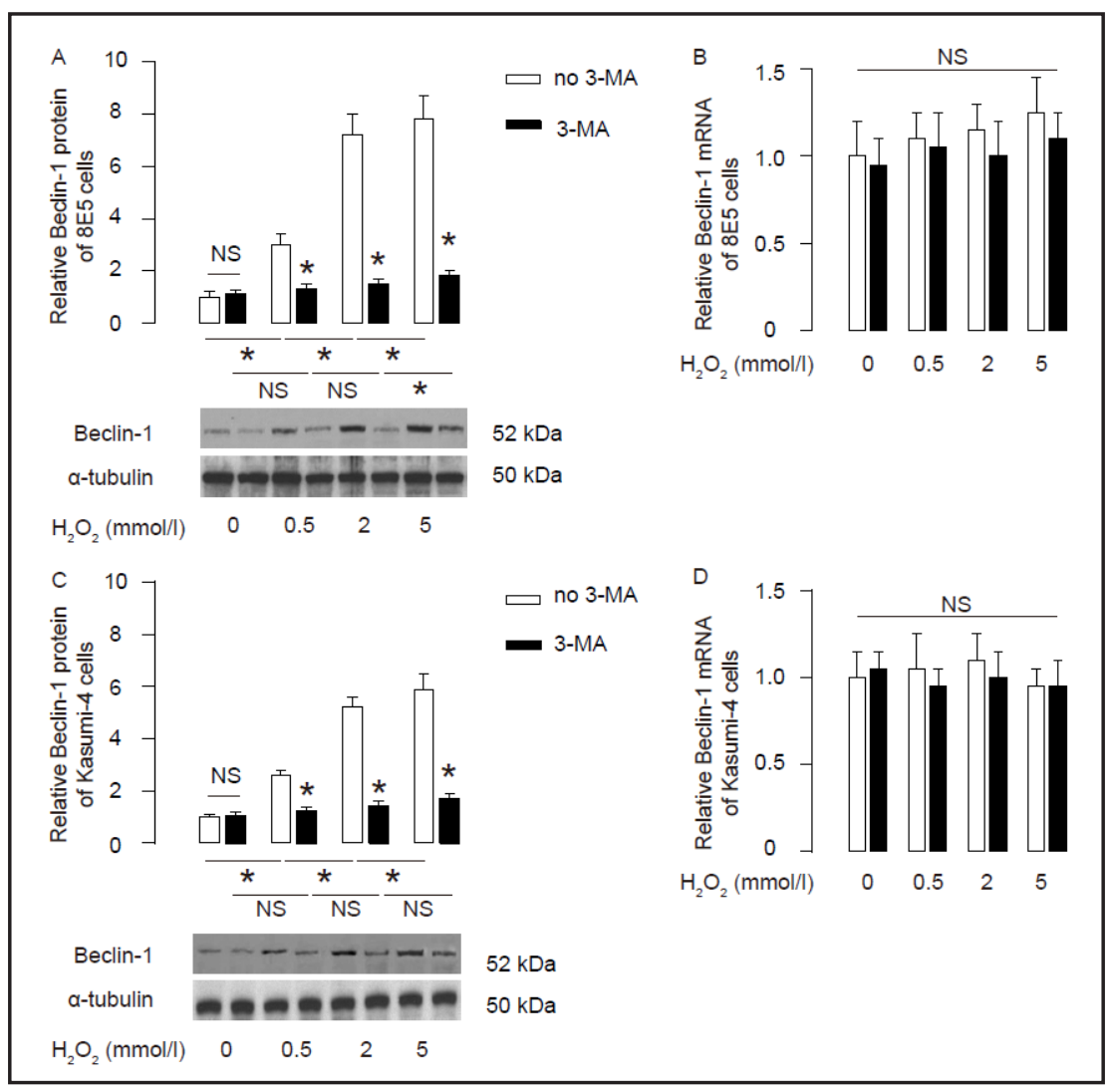

3-MA ( $5 \mathrm{mmol} / \mathrm{l})$. We found that high-dose hydrogen peroxide decreased $8 \mathrm{E} 5$ cell survival in an CCK-8 assay, while low-dose hydrogen peroxide did not significantly decrease 8E5 cell survival (Fig. 2A), consistent with apoptosis data. However, when autophagy was suppressed by 3-MA, low-dose hydrogen peroxide already significantly decreases $8 \mathrm{E} 5$ cell survival (Fig. 2A). Similarly, we found that high-dose hydrogen peroxide decreased Kasumi-4 cell survival, while low-dose hydrogen peroxide did not significantly decrease Kasumi-4 cell survival (Fig. 2B), consistent with apoptosis data. However, when autophagy was suppressed by 3-MA, low-dose hydrogen peroxide already significantly decreases Kasumi-4 cell survival (Fig. 2B). Together, these data suggest that hydrogen peroxide not only increases apoptotic death of PL cells, but also increases PL cell autophagy to contradict hydrogen peroxide-induced apoptotic cell death at low dose.

\section{KARGER}


Fig. 4. Hydrogen peroxide modulates miR-93, which targets Beclin-1 to regulate PL cell autophagy. (A) Among all predicted binding miRNAs, we found that miR-93 targeted the 135-141 base pairs of 3'-UTR of Beclin-1 mRNA. (BC) Moreover, miR-93 levels were found to be dose-dependently inhibited by hydrogen peroxide in 8E5 cells (B), and in Kasumi-4 cells (C). ${ }^{*} \mathrm{p}<0.05 . \mathrm{N}=5$.

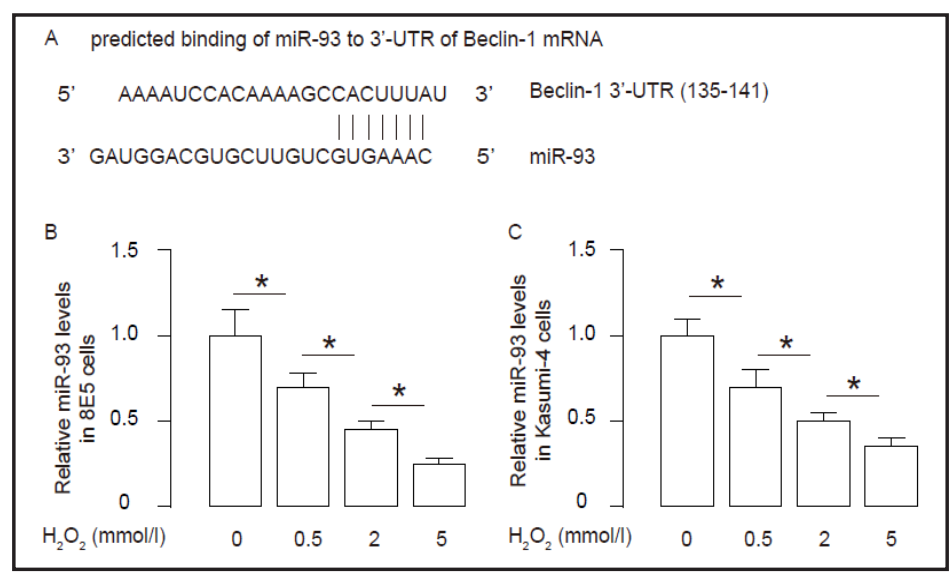

Hydrogen peroxide increases Beclin-1 to activate PL autophagy

We next examined the effects of hydrogen peroxide on Beclin-1, a key autophagyassociated protein, in PL cells. We gave hydrogen peroxide at different doses $(0,0.5,2$ and $5 \mathrm{mmol} / \mathrm{l}$, respectively) to PL cells, with or without an autophagy inhibitor 3-MA ( $5 \mathrm{mmol} / \mathrm{l})$. We found that hydrogen peroxide dose-dependently upregulated Beclin-1 in 8E5 cells, which was significantly suppressed by 3-MA (Fig. 3A). However, the Beclin-1 mRNA was not affected by hydrogen peroxide (Fig. 3B). Similarly, we found that hydrogen peroxide dosedependently upregulated Beclin-1 in Kasumi-4 cells, which was significantly suppressed by 3-MA (Fig. 3C). However, the Beclin-1 mRNA was not affected by hydrogen peroxide (Fig. 3D). These data suggest that hydrogen peroxide dose-dependently increases Beclin-1 levels and cell autophagy in PL cells, which may contribute to its chemo-resistance. Moreover, the regulation of Beclin-1 by oxidative stress may be at post-transcriptional level.

Hydrogen peroxide modulates miR-93, which targets Beclin-1 to regulate PL cell autophagy

Since miRNAs are critical regulators for protein translation, we performed bioinformatics studies to screen miRNAs that may target 3'-UTR of Beclin-1 mRNA, and were regulated by hydrogen peroxide treatment. Among all predicted binding miRNAs, we found that miR93 targeted the 135-141 base pairs of 3'-UTR of Beclin-1 mRNA (Fig. 4A). Moreover, miR93 levels were found to be dose-dependently inhibited by hydrogen peroxide in 8E5 cells (Fig. 4B), and in Kasumi-4 cells (Fig. 4C). Together, these data suggest that miR-93 may be a Beclin-1-targeting miRNA that is suppressed by hydrogen peroxide treatment in PL cells.

MiR-93 inhibits Beclin-1 protein translation in PL cells

In order to verify that the binding of miR-93 to the 3'-UTR of Beclin-1 mRNA is functional, we either overexpressed miR-93, or inhibited miR-93 (by antisense of miR-93; as-miR-93) in both PL cell lines. The PL cells were also transfected with a plasmid carrying a null sequence as a control (null). The overexpression or inhibition of miR-93 in PL cells was confirmed by RT-qPCR (Fig. 5A). MiR-93-modified PL cells were then transfected with $1 \mu$ g plasmids carrying luciferase reporter for 3'-UTR of Beclin-1 mRNA. Moreover, null-transfected PL cells were also transfected with $1 \mu \mathrm{g}$ plasmids carrying luciferase reporter for 3'-UTR of Beclin-1 mRNA with one mutate at the miR-93 binding site (mut). The luciferase activities were quantified in miR-93-modified PL cells, suggesting that miR-93 specifically targets 3'-UTR of Beclin-1 mRNA to inhibit its translation (Fig. 5B). Thus, our data suggest that the binding of miR-93 to the 3'-UTR of Beclin-1 mRNA in PL cells is functional.

\section{MiR-93 levels predict the outcome of chemotherapy of PL patients}

Next, we investigated whether the levels of miR-93 in peripheral leukemia cells after chemo-therapy may predict overall survival of PL patients. The 40 PL patients (aged 2-10 year-old) who received same chemotherapy were selected in this study. One month after treatment, levels of miR-93 in peripheral leukemia cells were taken for examination of miR-93 levels. Then, the patients were followed-up for 5 years. The median value of all 40 


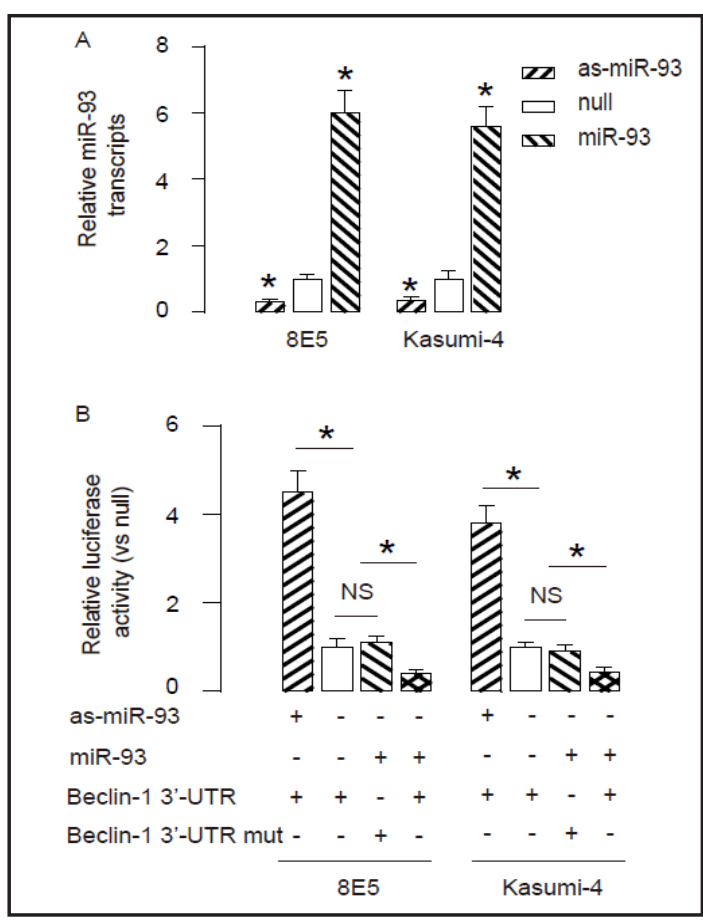

Fig. 5. MiR-93 inhibits Beclin-1 protein translation in PL cells. (A) In order to verify that the binding of miR-93 to the 3'-UTR of Beclin-1 mRNA is functional, we either overexpressed miR-93, or inhibited miR93 (by antisense of miR-93; as-miR-93) in both PL cell lines. The PL cells were also transfected with a plasmid carrying a null sequence as a control (null). The overexpression or inhibition of miR-93 in PL cells was confirmed by RT-qPCR. (B) MiR-93-modified PL cells were then transfected with $1 \mu \mathrm{g}$ plasmids carrying luciferase reporter for 3'-UTR of Beclin-1 mRNA. Moreover, null-transfected PL cells were also transfected with $1 \mu \mathrm{g}$ plasmids carrying luciferase reporter for mutated 3'-UTR of Beclin-1 mRNA at the miR-93 binding site (mut). The luciferase activities were quantified in miR-93-modified PL cells. ${ }^{*} \mathrm{p}<0.05$. NS: non-significant. $\mathrm{N}=5$.

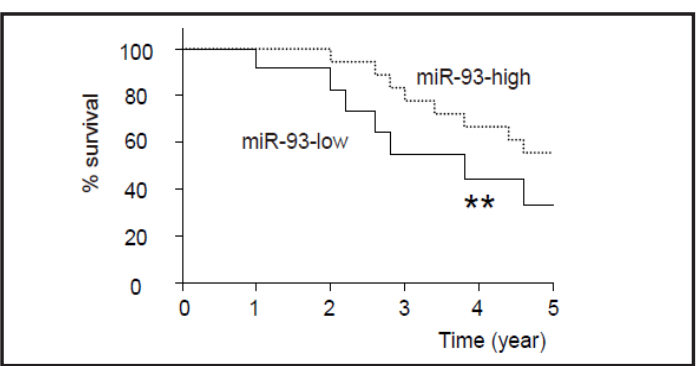

Fig. 6. MiR-93 levels predict the outcome of chemotherapy of PL patients. The 40 PL patients (aged 2-10 year-old) who received same chemotherapy were selected in this study. One month after treatment, levels of miR-93 in peripheral leukemia cells were taken for examination of miR-93 levels. Then, the patients were followed-up for 5 years. The median value of all 40 cases was chosen as the cutoff point for separating miR-93-high cases $(n=20)$ from miR93-low cases $(n=20)$. Kaplan-Meier curves were performed, showing that miR-93-low PL patients had a significantly poorer survival, compared to miR-93high PL patients. ${ }^{* *} \mathrm{p}<0.01 . \mathrm{N}=40$.

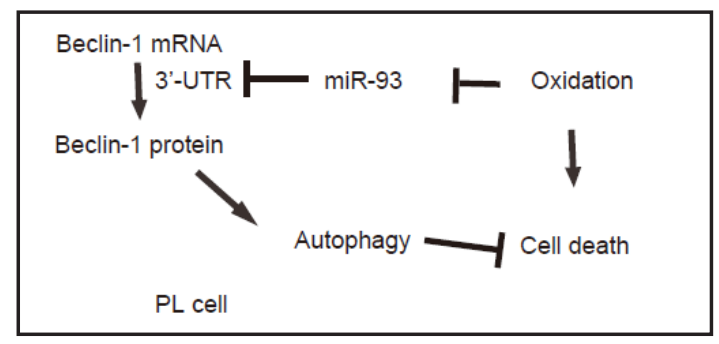

Fig. 7. Schematic of the model. Chemotherapy may decrease miR-93 levels in PL cells, which subsequently upregulates Beclin-1 to increase PL cell autophagy to antagonize hydrogen peroxide-induced cell death. The levels of depression of miR-93 may decide the activation of autophagic cell survival of PL cells against chemo-therapy and the outcome of the chemo-treatment.

cases was chosen as the cutoff point for separating miR-93-high cases $(n=20)$ from miR93-low cases $(n=20)$. Kaplan-Meier curves were performed, showing that miR-93-low PL patients had a significantly poorer survival, compared to miR-93-high PL patients (Fig. 6). Together, the findings in the current study suggest that chemotherapy may decrease miR-93 levels in PL cells, which subsequently upregulates Beclin-1 to increase PL cell autophagy to antagonize hydrogen peroxide-induced cell death. The levels of depression of miR-93 may decide the activation of autophagic cell survival of PL cells against chemo-therapy and the outcome of the chemo-treatment (Fig. 7).

\section{Discussion}

Chemotherapy induces mitotic arrest at concentrations typically used in human tumor cell (including PL cells) culture. On the other hand, the compromised effects of chemotherapy on cancer mitotic arrest and cell death may be resulting from the molecular responses of 
cancer cells to oxidative stress, in which enhanced survival is reached by activation of cell autophagy.

To identify cellular and molecular markers of resistance or sensitivity to chemotherapyassociated oxidative stress, great efforts have been performed by different researchers. Although a number of candidates have been identified, including proteasome subunits, cyclin G1, and solute carrier genes [42-46], so far a validated biomarker to be used in clinic for predicting the outcome of chemotherapy has not been achieved.

In the current study, we analyzed the effects of hydrogen peroxide (as an oxidase stress induced in chemotherapy) on the cell viability and autophagy of PL cells. We found that hydrogen peroxide decreased PL cell viability only at high dose. Similarly, hydrogen peroxide only induced significant cell apoptosis at high dose. Interestingly, inhibition of cell autophagy significantly increased cell death at low dose treatment of hydrogen peroxide, suggesting that the effects of low-dose hydrogen peroxide on PL cell death might be contradicted by enhanced autophagy-associated cell survival.

Here, we found a regulatory axis miR-93/Beclin-1 in PL cells in response to oxidase stress. We have examined all Beclin-1-targeting miRNAs and only the levels of miR-93 were altered in our experimental settings. Moreover, besides the data shown here, we also found that miR-93 levels were unaltered by peroxidase at the presence of 3-MA. Furthermore, the miR-93-modified cells still regulated Beclin-1 in response to hydrogen peroxide, which seemingly resulted from the incompletely inhibition of miR-93 by as-miR-93. The loss of Beclin-1 regulation by hydrogen peroxide may be seen in miR-93-Knockout cells.

In line with this view, it seemed that hydrogen peroxide induce both apoptotic cell death and autophagic cell survival in PL cells, and autophagy appears to be a negative feedback of PL cells to antagonize the toxicity of hydrogen peroxide-induced oxidative stress, which generated a harsh environment for PL cells. In order to survive, PL cells decreased miR93 levels to induce upregulation of Beclin-1 to augment autophagic cell survival. The levels of miR-93 depression and Beclin-1 upregulation may decide the levels of PL cells against chemotherapy. Here, we used 2 different PL lines (8E5 and Kasumi-4) and achieved same result, which potentially excluded a possibility of cell-line dependence of the current findings.

Together, our data shed light on a previously non-appreciated signaling regulatory pathway that decides the chemotherapeutic outcome against PL. Future experiments may be applied to further dissect the details of the pathway, e.g. other involved key proteins, other involved miRNAs, and the clinic relevance. Our study also suggests that strategies that increase miR-93 levels or inhibit cell autophagy may improve the outcome of PL chemotherapy.

\section{Acknowledgements}

This work is supported by Science and Technology Department of Hebei Province (NO: 152777206).

\section{Disclosure Statement}

The authors have declared that no competing interests exist.

\section{References}

1 Ma J, Hua J, Sha Y, Xie Y: The effect of tlx3 expression on the prognosis of pediatric $t$ cell acute lymphocytic leukemia--a systematic review. Tumour Biol 2014;35:8439-8443.

2 Wu X, Yang N, Zhou WH, Xu J, Chen JJ, Zheng FM, Long ZJ, Yue CF, Ai KX, Liu LL, Wan XY, Liu Q: Up-regulation of p21 inhibits trail-mediated extrinsic apoptosis, contributing resistance to saha in acute myeloid leukemia cells. Cell Physiol Biochem 2014;34:506-518.

3 Zhao S, Zhang Y, Sha K, Tang Q, Yang X, Yu C, Liu Z, Sun W, Cai L, Xu C, Cui S: Kras (g12d) cooperates with aml1/eto to initiate a mouse model mimicking human acute myeloid leukemia. Cell Physiol Biochem 2014;33:78-87. 


\section{Cellular Physiology Cell Physiol Biochem 2016;39:1827-1836 and BiOChemistry \begin{tabular}{l|l} 
DOI: 10.1159/000447882 & (c) 2016 The Author(s). Published by S. Karger AG, Basel \\
www.karger.com/cpb
\end{tabular} \\ Wu et al.: Autophagy in PL Cell Survival}

4 Wang Y, Zhou L, Chen J, Li J, He L, Wu P, Wang M, Tong N, Zhang Z, Fang Y: Association of the 3'utr foxo3a polymorphism rs4946936 with an increased risk of childhood acute lymphoblastic leukemia in a chinese population. Cell Physiol Biochem 2014;34:325-332.

5 Liang H, Li X, Wang L, Yu S, Xu Z, Gu Y, Pan Z, Li T, Hu M, Cui H, Liu X, Zhang Y, Xu C, Guo R, Lu Y, Yang B, Shan H: Micrornas contribute to promyelocyte apoptosis in as2o3-treated apl cells. Cell Physiol Biochem 2013;32:1818-1829.

6 Arico M, Ziino O, Valsecchi MG, Cazzaniga G, Baronci C, Messina C, Pession A, Santoro N, Basso G, Conter V, Italian Association of Pediatric H, Oncology: Acute lymphoblastic leukemia and down syndrome: Presenting features and treatment outcome in the experience of the italian association of pediatric hematology and oncology (aieop). Cancer 2008;113:515-521.

7 Chang M, Raimondi SC, Ravindranath Y, Carroll AJ, Camitta B, Gresik MV, Steuber CP, Weinstein H: Prognostic factors in children and adolescents with acute myeloid leukemia (excluding children with down syndrome and acute promyelocytic leukemia): Univariate and recursive partitioning analysis of patients treated on pediatric oncology group (pog) study 8821. Leukemia 2000;14:1201-1207.

8 Liu J, Zhang X, Liu A, Liu S, Zhang L, Wu B, Hu Q: Berberine induces apoptosis in p53-null leukemia cells by down-regulating xiap at the post-transcriptional level. Cell Physiol Biochem 2013;32:1213-1224.

9 Arakawa Y, Kato M, Koh K, Hanada R: Unrelated cord blood and bone marrow transplantation in pediatric leukemia. Pediatr Int 2014;56:647-650.

10 Shaw PJ, Kan F, Woo Ahn K, Spellman SR, Aljurf M, Ayas M, Burke M, Cairo MS, Chen AR, Davies SM, Frangoul H, Gajewski J, Gale RP, Godder K, Hale GA, Heemskerk MB, Horan J, Kamani N, Kasow KA, Chan KW, Lee SJ, Leung WH, Lewis VA, Miklos D, Oudshoorn M, Petersdorf EW, Ringden O, Sanders J, Schultz KR, Seber A, Setterholm M, Wall DA, Yu L, Pulsipher MA: Outcomes of pediatric bone marrow transplantation for leukemia and myelodysplasia using matched sibling, mismatched related, or matched unrelated donors. Blood 2010;116:4007-4015.

11 Li DH, Pan ZK, Ye F, An HX, Wu JX: S-1-based versus 5-fu-based chemotherapy as first-line treatment in advanced gastric cancer: A meta-analysis of randomized controlled trials. Tumour Biol 2014;35:82018208.

12 Lu ZM, Luo TH, Nie MM, Fang GE, Ma LY, Xue XC, Wei G, Ke CW, Bi JW: Influence of ercc1 and ercc4 polymorphisms on response to prognosis in gastric cancer treated with folfox-based chemotherapy. Tumour Biol 2014;35:2941-2948.

13 Wu XJ, Yuan P, Li ZY, Bu ZD, Zhang LH, Wu AW, Zong XL, Li SX, Shan F, Ji X, Ren H, Ji JF: Cytoreductive surgery and hyperthermic intraperitoneal chemotherapy improves the survival of gastric cancer patients with ovarian metastasis and peritoneal dissemination. Tumour Biol 2013;34:463-469.

14 Shin D, Kwon HY, Sohn EJ, Nam MS, Kim JH, Lee JC, Ryu SY, Park B, Kim SH: Upregulation of death receptor 5 and production of reactive oxygen species mediate sensitization of pc-3 prostate cancer cells to trail induced apoptosis by vitisin a. Cell Physiol Biochem 2015;36:1151-1162.

15 Saleh AM, Aljada A, El-Abadelah MM, Sabri SS, Zahra JA, Nasr A, Aziz MA: The pyridone-annelated isoindigo (5'-cl) induces apoptosis, dysregulation of mitochondria and formation of ros in leukemic hl-60 cells. Cell Physiol Biochem 2015;35:1958-1974.

16 Yun M, Lee D, Park MN, Kim EO, Sohn EJ, Kwon BM, Kim SH: Cinnamaldehyde derivative (cb-pic) sensitizes chemo-resistant cancer cells to drug-induced apoptosis via suppression of mdr1 and its upstream stat3 and akt signalling. Cell Physiol Biochem 2015;35:1821-1830.

17 Xiong Y, Ye T, Wang M, Xia Y, Wang N, Song X, Wang F, Liu L, Zhu Y, Yang F, Wei Y, Yu L: A novel cinnamide ylt26 induces breast cancer cells apoptosis via ros-mitochondrial apoptotic pathway in vitro and inhibits lung metastasis in vivo. Cell Physiol Biochem 2014;34:1863-1876.

18 Li X, Huo X, Zhang C, Ma X, Han F, Wang G: Role of continuous high thoracic epidural anesthesia in hippocampal apoptosis after global cerebral ischemia in rats. Cell Physiol Biochem 2014;34:1227-1240.

19 Xie M, Yi X, Wang R, Wang L, He G, Zhu M, Qi C, Liu Y, Ye Y, Tan S, Tang A: 14-thienyl methylene matrine (yyj18), the derivative from matrine, induces apoptosis of human nasopharyngeal carcinoma cells by targeting mapk and pi3k/akt pathways in vitro. Cell Physiol Biochem 2014;33:1475-1483.

20 Zhu Y, Xia Y, Ye T, Shi X, Song X, Liu L, Zeng J, Wang N, Luo Y, Han Y, Yu L: A novel small-molecule ylt205 induces apoptosis in human colorectal cells via mitochondrial apoptosis pathway in vitro and inhibits tumor growth in vivo. Cell Physiol Biochem 2014;33:933-944.

21 Green DR, Levine B: To be or not to be? How selective autophagy and cell death govern cell fate. Cell 2014;157:65-75.

22 Chen Y, Liu H, Guan Y, Wang Q, Zhou F, Jie L, Ju J, Pu L, Du H, Wang X: The altered autophagy mediated by tfeb in animal and cell models of amyotrophic lateral sclerosis. Am J Transl Res 2015;7:1574-1587. 


\section{Cellular Physiology Cell Physiol Biochem 2016;39:1827-1836 and Biochemistry Published \begin{tabular}{l|l} 
DOI: 10.1159/000447882 & (c) 2016 The Author(s). Published by S. Karger AG, Basel \\
www.karger.com/cpb
\end{tabular} \\ Wu et al.: Autophagy in PL Cell Survival}

23 Chen J, Wang Q Yin FQ, Zhang W, Yan LH, Li L: Mtrr silencing inhibits growth and cisplatin resistance of ovarian carcinoma via inducing apoptosis and reducing autophagy. Am J Transl Res 2015;7:1510-1527.

24 Nandi SS, Duryee MJ, Shahshahan HR, Thiele GM, Anderson DR, Mishra PK: Induction of autophagy markers is associated with attenuation of mir-133a in diabetic heart failure patients undergoing mechanical unloading. Am J Transl Res 2015;7:683-696.

25 Cheng Y, Wang B, Zhou H, Dang S, Jin M, Shi Y, Hao L, Yang Z, Zhang Y: Autophagy is required for the maintenance of liver progenitor cell functionality. Cell Physiol Biochem 2015;36:1163-1174.

26 Levine B, Kroemer G: Autophagy in the pathogenesis of disease. Cell 2008;132:27-42.

27 Wang XM, Yang YJ, Wu YJ, Zhang Q, Qian HY: Attenuating hypoxia-induced apoptosis and autophagy of mesenchymal stem cells: The potential of sitagliptin in stem cell-based therapy. Cell Physiol Biochem 2015;37:1914-1926.

28 Zhang T, Tian F, Wang J, Jing J, Zhou SS, Chen YD: Endothelial cell autophagy in atherosclerosis is regulated by mir-30-mediated translational control of atg6. Cell Physiol Biochem 2015;37:1369-1378.

29 Zhang T, Tian F, Wang J, Jing J, Zhou SS, Chen YD: Atherosclerosis-associated endothelial cell apoptosis by mir-429-mediated down regulation of bcl-2. Cell Physiol Biochem 2015;37:1421-1430.

30 Li C, Liu Y, Liu H, Zhang W, Shen C, Cho K, Chen X, Peng F, Bi Y, Hou X, Yang Z, Zheng Z, Wang K, Wang X, Zhang J, Zhong C, Zou H, Zhang X, Zhao S: Impact of autophagy inhibition at different stages on cytotoxic effect of autophagy inducer in glioblastoma cells. Cell Physiol Biochem 2015;35:1303-1316.

31 Di Leva G, Croce CM: Mirna profiling of cancer. Curr Opin Genet Dev 2013;23:3-11.

32 Pereira DM, Rodrigues PM, Borralho PM, Rodrigues CM: Delivering the promise of mirna cancer therapeutics. Drug Discov Today 2013;18:282-289.

33 Mei Q, Li F, Quan H, Liu Y, Xu H: Busulfan inhibits growth of human osteosarcoma through mir-200 family micrornas in vitro and in vivo. Cancer Sci 2014;105:755-762.

34 Wang F, Xiao W, Sun J, Han D, Zhu Y: Mirna-181c inhibits egfr-signaling-dependent mmp9 activation via suppressing akt phosphorylation in glioblastoma. Tumour Biol 2014;35:8653-8658.

35 Liu G, Jiang C, Li D, Wang R, Wang W: Mirna-34a inhibits egfr-signaling-dependent mmp7 activation in gastric cancer. Tumour Biol 2014;35:9801-9806.

36 Xiao X, Zhou L, Cao P, Gong H, Zhang Y: Microrna-93 regulates cyclin g2 expression and plays an oncogenic role in laryngeal squamous cell carcinoma. Int J Oncol 2015;46:161-174.

37 Ohta K, Hoshino H, Wang J, Ono S, Iida Y, Hata K, Huang SK, Colquhoun S, Hoon DS: Microrna-93 activates c-met/pi3k/akt pathway activity in hepatocellular carcinoma by directly inhibiting pten and cdkn1a. Oncotarget 2015;6:3211-3224.

38 Yang IP, Tsai HL, Hou MF, Chen KC, Tsai PC, Huang SW, Chou WW, Wang JY, Juo SH: Microrna-93 inhibits tumor growth and early relapse of human colorectal cancer by affecting genes involved in the cell cycle. Carcinogenesis 2012;33:1522-1530.

39 Tang Q, Zou Z, Zou C, Zhang Q Huang R, Guan X, Li Q, Han Z, Wang D, Wei H, Gao X, Wang X: Microrna-93 suppress colorectal cancer development via wnt/beta-catenin pathway downregulating. Tumour Biol 2015;36:1701-1710.

40 Xiao ZG, Deng ZS, Zhang YD, Zhang Y, Huang ZC: Clinical significance of microrna-93 downregulation in human colon cancer. Eur J Gastroenterol Hepatol 2013;25:296-301.

41 Coronnello C, Benos PV: Comir: Combinatorial microrna target prediction tool. Nucleic Acids Res 2013;41:W159-164.

42 Rouzier R, Rajan R, Wagner P, Hess KR, Gold DL, Stec J, Ayers M, Ross JS, Zhang P, Buchholz TA, Kuerer H, Green M, Arun B, Hortobagyi GN, Symmans WF, Pusztai L: Microtubule-associated protein tau: A marker of paclitaxel sensitivity in breast cancer. Proc Natl Acad Sci U S A 2005;102:8315-8320.

43 Ahmed AA, Mills AD, Ibrahim AE, Temple J, Blenkiron C, Vias M, Massie CE, Iyer NG, McGeoch A, Crawford R, Nicke B, Downward J, Swanton C, Bell SD, Earl HM, Laskey RA, Caldas C, Brenton JD: The extracellular matrix protein tgfbi induces microtubule stabilization and sensitizes ovarian cancers to paclitaxel. Cancer Cell 2007;12:514-527.

44 Swanton C, Marani M, Pardo O, Warne PH, Kelly G, Sahai E, Elustondo F, Chang J, Temple J, Ahmed AA, Brenton JD, Downward J, Nicke B: Regulators of mitotic arrest and ceramide metabolism are determinants of sensitivity to paclitaxel and other chemotherapeutic drugs. Cancer Cell 2007;11:498-512.

45 Whitehurst AW, Bodemann BO, Cardenas J, Ferguson D, Girard L, Peyton M, Minna JD, Michnoff C, Hao W, Roth MG, Xie XJ, White MA: Synthetic lethal screen identification of chemosensitizer loci in cancer cells. Nature 2007;446:815-819.

46 Pusztai L: Markers predicting clinical benefit in breast cancer from microtubule-targeting agents. Ann Oncol 2007; 18:Sxii15-20. 